\title{
A simple technique for accelerating the growth of the kidney disease bacterium Renibacterium salmoninarum on a commonly used culture medium (KDM2)
}

\author{
T. P. T. Evelyn, G. R. Bell, L. Prosperi-Porta, J. E. Ketcheson
}

Department of Fisheries and Oceans, Biological Sciences Branch, Pacific Biological Station, Nanaimo, British Columbia, Canada V9R 5K6

\begin{abstract}
A simple technique for significantly accelerating the growth of Renibacterium salmoninarum (Rs), causative agent of bacterial kidney disease in salmonids, is described and evaluated. The technique is based on the wellknown phenomenon, referred to as 'satellitism' or 'crossfeeding', in which a fastidious organism is induced to grow by placing it on an agar culture medium next to a nonfastidious feeder or 'nurse' organism. In the present procedure, the nurse organism is actually a stock culture of Rs, a heavy suspension of which is drop-inoculated ( $25 \mu \mathrm{l}$ aliquot) onto the centre of a KDM2 culture plate. Samples suspected of containing Rs are peripherally drop-inoculated on the plate. Growth of the nurse culture occurs rapidly and modif cells in the peripheral samples is greatly accelerated. The effect is most pronounced when the number of Rs cells in peripheral samples is low. The mechanism underlying growth acceleration was not investigated
\end{abstract}

Renibacterium salmoninarum (Rs), the agent responsible for bacterial kidney disease (BKD) in salmonids, is a frustratingly, slow-growing organism. With samples containing low numbers of Rs cells, such as those derived from subclinical infections, incubation times of ca $6 \mathrm{wk}$ are commonly required for visible growth of the pathogen on agar media. In fact, one group of researchers recently advised using incubation periods of $12 \mathrm{wk}$ before considering samples negative for Rs (Gudmundsdottir et al. 1988). This slow-growing property of Rs has discouraged research on the pathogen and has led to the development of non-cultural techniques for its detection (Pascho et al. 1987).

In this report, we describe a simple technique for significantly accelerating the growth of Rs. The technique is based on the well-known phenomenon, referred to as 'satellitism' (Salle 1954, p. 266-267) or 'cross- feeding (Davis et al. 1973, p. 61), in which a fastidious organism is induced to grow by placing it on an agar medium next to an unrelated 'nurse' organism. In the present case, the nurse organism is actually a stock culture of Rs rather than another species of bacterium. The procedure suggested itself when it was observed that samples containing very low numbers of Rs cells always exhibited improved growth if they occurred on the agar medium adjacent to samples containing large numbers of Rs cells. Further, it was frequently noted, in nutritional studies with Rs, that heavy inocula allowed growth on or in media that would not support growth of lighter inocula (unpubl. data).

Materials and methods. Five experiments were conducted. The first 3 evaluated the nurse culture procedure using stock isolates of Rs (Isolates 143, 384, and 8894) obtained in this laboratory from salmonids that died of typical BKD. The fourth experiment evaluated the procedure with Rs isolates obtained directly from infected kidney tissues of 2 yearling chinook salmon (Oncorhynchus tshawytscha), dead due to BKD. In the fifth experiment, the nurse culture procedure was assessed as a method for screening fish for Rs. The population of fish selected for the survey was a group of cultured, under-yearling chinook salmon that had been shown to be subclinically infected with Rs using the fluorescent antibody technique (Bullock \& Stuckey 1975).

The stock isolates of Rs (Isolates 143, 384, and 8894) used were typical of Rs in that they were small $(0.5 \times$ $1.0 \mu \mathrm{m})$, non-motile, non-sporeforming, Gram-positive rods that grew best at $15^{\circ} \mathrm{C}$. They also required cysteine for growth and reacted strongly with anti-Rs serum (Grand Island Biological Company) in the 
agglutination, immunodiffusion, and fluorescent antibody staining reactions. The Rs isolates obtained directly from infected kidney tissues were typical of the pathogen in those features for which they were tested their Gram reaction, morphology, and serology.

The medium used, KDM2 (Evelyn 1977), was supplemented with $10 \%(\mathrm{v} / \mathrm{v})$ newborn bovine serum (Flow Laboratories, Inc.) and also contained 0.005\% (w/v) cycloheximide (Sigma Chemical Company) (Austin et al. 1985) to reduce the chances of fungal contamination.

Samples to be tested for their Rs content were dropinoculated (25 $\mu \mathrm{l}$ replicate drops) (Miles \& Misra 1938) peripherally on each of 2 plates of KDM2. One of the plates was also drop-inoculated, in the centre, with a nurse culture $(25 \mu 1)$, care being taken not to spatter the nurse culture. The other (control) plate was not inoculated with the nurse culture.

Samples, in the case of the Rs stock isolates, consisted of 29-d-old KDM2-grown Rs cells that had been suspended in cold, sterile peptone $(0.1 \%)$ - saline $(0.9 \% \mathrm{NaCl})$ (PS) to a standard turbidity $(1.25 \mathrm{OD}$ at $540 \mathrm{~nm}$ ) and diluted to $10^{-6}$ in 10 -fold steps in PS. Samples, in the case of kidney tissue, consisted of PSdiluted kidney homogenates (10\% w/v in PS) (Expt 4) or the undiluted kidney homogenates (Expt 5).

Two Rs isolates (143 and 384) were tested as nurse cultures. The nurse cultures took the form of heavy suspensions (1.25 OD at $540 \mathrm{~nm}$ in PS) of 29-d-old KDM2-grown Rs cells.

Following imbibition by the medium of the $25 \mu \mathrm{l}$ drops of inoculum, the plates were sealed in plastic bags to prevent desiccation, and incubated at $15^{\circ} \mathrm{C}$.

Table 1 Renibacterium salmoninarum. Growth of Rs Isolate 143 on KDM2 culture medium at Day 19 and 25 in the presence and absence of a nurse culture. Growth: average tacolony count (based on 8 replicate values) per $25 \mu \mathrm{l}$ aliguot of a variously diluted standard suspension (1.25 OD at $540 \mathrm{~nm}$ ) of 29 -d-old Rs 143 cells ( \pm 1 SD). Reading horizontally, colony counts with different superscript letters are significantly different from each other $(p<0.01$ ) using the $t$-test (Snedecor 1946, p. 77) on natural log transformed data. Non-nursed samples: colonies were visualized and counted with a microscope $(\times 250)$; view with the naked eye is shown in Fig. 1 nr: not recounted; growth was becoming confluent

\begin{tabular}{|ccccc|}
\hline $\begin{array}{c}\text { Incu- Dilu- } \\
\text { bation tion } \\
\text { period } \\
\text { (d) }\end{array}$ & & Self-nursed & Rs 384-nursed & Un-nursed \\
\hline \multirow{2}{*}{19} & $10^{-5}$ & $219.5( \pm 17.2)^{\mathrm{A}}$ & $215.91 \pm 20.3)^{\mathrm{A}}$ & $0^{\mathrm{B}}$ \\
& $10^{-6}$ & $17.6( \pm 2.9)^{\mathrm{A}}$ & $18.9( \pm 4.2)^{\mathrm{A}}$ & $0^{\mathrm{B}}$ \\
25 & $10^{-5}$ & $\mathrm{nr}$ & $\mathrm{nr}$ & $224.9( \pm 45.6)$ \\
& $10^{-6}$ & $17.6( \pm 2.9)^{\mathrm{A}}$ & $18.9( \pm 4.2)^{\mathrm{A}}$ & $19.4( \pm 2.4)^{\mathrm{A}}$ \\
& & & & \\
\end{tabular}

inverted, for periods indicated in Tables 1 to 4 (Results and discussion section). The resuitant Rs growth was measured in terms of the number of colonies produced from each $25 \mu \mathrm{l}$ drop of sample, or in terms of the amount of growth (biomass of Rs cells) produced from the sample. Colony counts were made using a stereomicroscope; the amount of growth produced was measured turbidometrically using the technique of Bell et al. (1988). In this technique, colonies resulting from the $25 \mu \mathrm{l}$ drop of sample were transferred, along with a standard size block of supporting agar, to a fixed volume of saline containing sufficient formalin to prevent further bacterial growth. Rs cells were suspended by agitation, and, following settling of the agar block, the turbidity of the cell suspension was read at 540 nim.

Results and discussion. Rapid growth of nurse cultures invariably occurred due to the heavy inoculum used. This growth modified conditions in the culture plate such that Rs cells grew at a greatly accelerated rate when present in low numbers in the samples. This acceleration occurred whether or not cells in the samples were nursed with homologous Rs or with another Rs culture (Tables 1 and 2). Countable colonies were evident on nurse culture plates at Day 19 but not on plates lacking nurse cultures. Samples on un-nursed plates produced countable colonies only by Day 25, but even at this stage, a magnification of $250 \times$ (twice that routinely used for colony counting) was required for their enumeration. Fig. 1 illustrates the results, as seen with the naked eye, for nursed and un-nursed samples containing Rs 348 at Day 25. It is evident that even at this time, colonies in un-nursed samples would have escaped attention of using the naked eye. This held true even though the colony counts obtained using the microscope were the same for the nursed and unnursed samples.

Table 2. Renibacterium salmoninarum. Growth of Rs Isolate 384 on KDM2 culture medium at Day 19 and 25 in the presence and absence of a nurse culture. Growth: average colony count (based on 8 replicate values) per 25 ul aliquot of a variously diluted standard suspension (1.25 OD at 540 $\mathrm{nm}$ ) of 29-d-old Rs 384 ceils ( \pm 1 SD). For further details see Table 1

\begin{tabular}{ccccc}
\hline $\begin{array}{c}\text { Incu- Dilu- } \\
\text { bation } \\
\text { period } \\
\text { (d) }\end{array}$ & Self-nursed & Rs 143-nursed & Un-nursed \\
\hline & & & \\
19 & $10^{-5}$ & $258.5( \pm 23.2)^{\mathrm{A}}$ & $239.4( \pm 37.2)^{\mathrm{A}}$ & $0^{\mathrm{B}}$ \\
& $10^{-6}$ & $19.9( \pm 5.5)^{\mathrm{A}}$ & $23.0( \pm 5.1)^{\mathrm{A}}$ & $0^{\mathrm{B}}$ \\
25 & $10^{-5}$ & $\mathrm{nr}$ & $\mathrm{nr}$ & $275.4( \pm 22.6)$ \\
& $10^{-6}$ & $19.9( \pm 5.5)^{\mathrm{A}}$ & $23.0( \pm 5.1)^{\mathrm{A}}$ & $22.0( \pm 4.4)^{\mathrm{A}}$ \\
& & & &
\end{tabular}




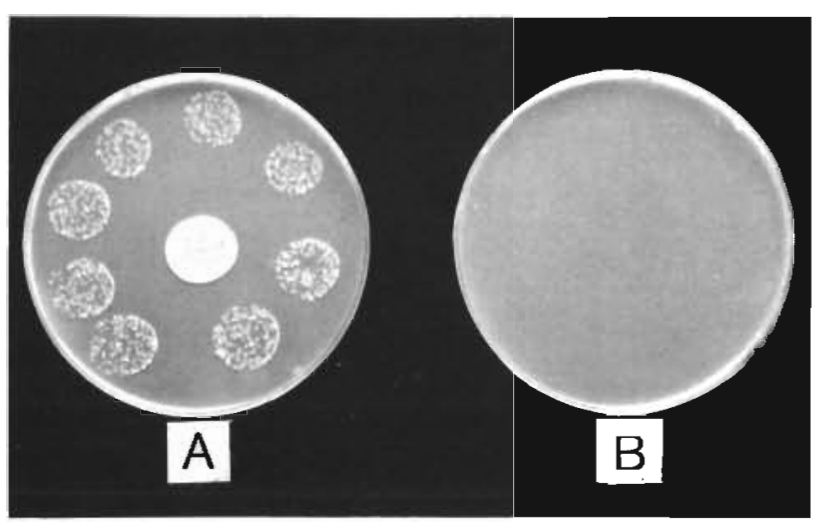

Fig. 1. Renibacterium salmoninarum. Growth at Day 25 of Rs Isolate 384 ( 8 peripheral areas of growth) on KDM2 plates provided with a nurse culture (Rs 143) (central area of growth, Plate A) and lacking the nurse culture (Plate B). Peripheral growth of Rs 384 on Plate $B$ was discernible only with the use of a microscope $(\times 250)$. Peripheral samples were 25 ul aliquots of a $10^{-5}$ dilution of a standardized Rs 384 cell suspension (1.25 OD at $540 \mathrm{~nm})$

Table 3 records the effect of the nurse culture technique in terms of the amount of growth produced (turbidity) and the number of colonies obtained. The advantage of the nurse culture technique was evident by the increased amount of growth produced, rather than in the colony counts obtained. There was no significant difference in colony counts between nursed and un-nursed samples (Table 3), probably because of the long ( $25 \mathrm{~d}$ ) incubation period used. (Again, colonies on un-nursed plates at Day 25 were so small that they would have been overlooked using the naked eye). The growth accelerating effect of the nurse culture was especially obvious with the more highly diluted samples, i.e., samples containing ca 200 Rs cells or less per 25 u (Table 3). This feature of the nurse culture technique makes it a very useful procedure for use with covertly infected fish (see later). With less highly diluted samples, i.e., samples containing 1000 Rs cells or more per $25 \mu$, the advantages of the nurse culture were not particularly obvious because growth in nursed and un-nursed samples appeared to be equally rapid (data not shown). In samples containing 1000 or more Rs cells per $25 \mu$, Rs cells appeared to 'nurse' each other into rapid growth.

Table 4 illustrates the effect of the nurse culture technique when applied to Rs-infected tissues rather than to stock cultures. In the absence of the nurse culture, growth at Day 28 was only obvious in kidney homogenate samples that had not been extensively diluted (the $10^{-1}$ to $10^{-2}$ dilutions). In contrast, growth at Day 28 on nursed plates was evident in samples at considerably higher dilutions. It may well be that the colony counts in the nursed and un-nursed tissue samples would have become equal with further incubation. However, this was not tested. An unavoidable conclusion, based on the $28 \mathrm{~d}$ incubation data, is that the nurse culture technique also increases the Rsdetecting sensitivity of the culture method when applied to infected tissues. This desirable effect appears to have been borne out by the results obtained in our final experiment. In this experiment, the nurse culture technique was evaluated as a screening procedure for Rs on a sample of 61 fish drawn from a population subclinically infected with Rs. At Day 28 of incubation, the number of fish found to be Rs-positive with nursed samples (44) was almost twice that with un-nursed samples (23) - an impressive gain in Rsdetecting sensitivity. Further, when 31 of the samples were incubated for an additional $14 \mathrm{~d}, 3$ more unnursed samples became Rs-positive (data not shown). In contrast, there was no increase in the number of nursed samples positive for Rs during this period. This suggested that all Rs-infected samples had registered positive by Day 28 when the nurse culture was used.

In the light of the foregoing results, we think that the nurse culture technique should greatly facilitate the detection of viable Rs in samples from covertly infected

Table 3. Renibacterium salmoninarum. Growth of Rs Isolates 384 and 8894 on KDM2 culture medium at Day 25 in the presence and absence of a nurse culture (Rs 384). Growth measured in terms of turbidity and number of colonies. Average turbidity values (based on 5 replicate values) and average colony counts (based on 4 to 8 replicate values) yielded by $25 \mu$ lof a variously diluted standard suspension $(1.25 \mathrm{OD}$ at $540 \mathrm{~nm}$ ) of 29 -d-old Rs cells ( $\pm 1 \mathrm{SD}$ ). For any given dilution of sample, values for turbidity or for colony counts differ significantly $(\mathrm{p}=<0.01$ ) when the superscript letter is different [ $\mathrm{t}$-test on natural log transformed data (Snedecor 1946, p. 77 for samples of equal size and p. 81-82 for samples of unequal size)]. NC: Not counted because large colonies tended to coalesce

\begin{tabular}{|c|c|c|c|c|c|}
\hline \multirow[t]{2}{*}{ Rs test-isolate } & \multirow[t]{2}{*}{ Dilution } & \multicolumn{2}{|c|}{ Turbidity } & \multicolumn{2}{|c|}{$N$} \\
\hline & & Nursed & Un-nursed & Nursed & Un-nursed \\
\hline \multirow[t]{2}{*}{384} & $10^{-4}$ & $0.280( \pm 0.032)^{\mathrm{A}}$ & $0.001( \pm 0.000)^{\mathrm{B}}$ & NC & $213.6( \pm 14.4)$ \\
\hline & $10^{-5}$ & $0.094( \pm 0.030)^{\mathrm{A}}$ & $0.001( \pm 0.000)^{\mathrm{B}}$ & $21.4( \pm 4.3)^{A}$ & $15.6( \pm 5.0)^{\mathrm{A}}$ \\
\hline \multirow[t]{2}{*}{8894} & $10^{-4}$ & $0.320( \pm 0.076)^{\mathrm{A}}$ & $0.033( \pm 0.021)^{\mathrm{B}}$ & $112.5( \pm 20.6)^{\mathrm{A}}$ & $105.6( \pm 7.2)^{\wedge}$ \\
\hline & $10^{-5}$ & $0.110( \pm 0.048)^{\mathrm{A}}$ & $0.001( \pm 0.000)^{\mathrm{B}}$ & $11.3( \pm 4.1)^{A}$ & $10.8( \pm 2.7)^{\mathrm{A}}$ \\
\hline
\end{tabular}


Table 4. Renibacterium salmoninarum. Growth of Rs from infected kidney tissue of 2 chinook salmon (Oncorhynchus tshawytscha) on KDM2 culture medium at Day 28 in the presence dind absence of a nurse culture (Rs 384). Dilution: of infected $10 \%$ kidney homogenate. Growth: average colony count (based on 4 replicate values) per 25, , al aliquot of variously diluted kidney homogenates ( $\pm 1 \mathrm{SD}$ ); TNTC = growth was confluent or colonies were too numerous to count

\begin{tabular}{|c|c|c|c|c|}
\hline \multirow{3}{*}{$\begin{array}{l}\text { Dilu- } \\
\text { tion }\end{array}$} & \multicolumn{4}{|c|}{ Growth } \\
\hline & \multicolumn{2}{|c|}{ Fish 1} & \multicolumn{2}{|c|}{ Fish 2} \\
\hline & Nursed & Unnursed & Nursed & $\begin{array}{l}\text { Un- } \\
\text { nursed }\end{array}$ \\
\hline $10^{-1}$ & TNTC & TNTC & TNTC & TNTC \\
\hline $10^{-2}$ & TNTC & TNTC & TNTC & TNTC \\
\hline $10^{-4}$ & TNTC & 0 & $37.5( \pm 13.9)$ & 0 \\
\hline $10^{-4}$ & $61.6( \pm 5.3)$ & 0 & $4.8( \pm 1.5)$ & 0 \\
\hline $10=$ & $6.5( \pm 2.0)$ & 0 & 0 & 0 \\
\hline $10^{-6}$ & 0.3 & 0 & 0 & 0 \\
\hline
\end{tabular}

fish, and that it should prove useful whenever there is a need to culture and/or enumerate the viable pathogen. We did not investigate the mechanism associated with the success of the nurse culture technique but several possibilities that require testing suggest themselves. The nurse culture may grow quickly because it is used in concentrated form, and this may provide the critical amounts of some needed, and endogenously stored, factor responsible for the initiation of rapid growth. Once growing, the nurse culture may act on the medium to (1) produce more of the needed (and presumably diffusible) growth factor, thus facilitating the growth of other Rs cells on the medium, or to (2) produce physical changes in the medium (e.g. changes in $\mathrm{pH}$ or surface tension) that render necessary growth factors more available to Rs cells. Conversely, the nurse culture may function by destroying inhibitory substances present in the medium.

Workers interested in using the technique may justifiably wonder whether they run the risk of obtaining false-positive results due to the possibility of spattering

Editorial responsibility: Managing Editor the nurse culture when applying it to culture plates. We think that the risk of this is insignificant. In the first place, we have not encountered problems due to spattering despite extensive use of the technique. In the second place, when spatter was deliberately achieved (by drop-inoculating the medium from a height in excess of 1 to $2 \mathrm{~cm}$ ), the resulting growth in the droplets was easily distinguished from that usually seen in plated samples.

\section{LITERATURE CITED}

Austin, B., Embley, T M., Goodfellow, M. (1985). Selective isolation of Renibacterium salmoninarum. Fedn eur. microbiol. Soc. (FEMS) Lett. 17: 111-114

Bell, G. R., Traxler, G. S., Dworschak, C. (1988). Development in vitro and pathogenicity of an erythromycin-resistant strain of Renibacterium salmoninarum, the causative agent of bacterial kidney disease in salmonids. Dis aquat. Org. $4: 19-25$

Bullock, G. L., Stuckey, H. M. (1975). Fluorescent antibody identification and detection of the Corynebacterium causing kidney disease in salmonids. J. Fish. Res. Bd Can. 32: 2224-2227

Davis, B. D., Dulbecco, R., Eisen, H. N., Ginsberg, H. S., Wood, B. W., Jr (1973). Microbiology, 2nd edn. Harper \& Row, Publishers Inc, New York, Evanston, San Francisco, London

Evelyn, T P. T (1977). An improved growth medium for the kidney disease bacterium and some notes on using the medium. Bull. Off. Int. Epiz. 87. 511-513

Gudmundsdottir, S., Benediktsdottir, E., Helgason, S. (1988). Comparative effectiveness of three different growth-media for primary isolation of Renibacterium salmoninarum. In: Fish Health Section, American Fisheries Society Conference Handbook. International Fish Health Conference, Vancouver, B.C., Canada, July 19-21 1988, p. 84

Miles, A. A., Misra, S. S. (1938). The estimation of the bactericidal power of the blood. J. Hyg. 38: 732-749

Pasch.o, R. J., Elliott, D. G., Mallet, R. W., Mulcahy, D. (1987). Comparison of five techniques for the detection of Renibacterium salmoninarum in adult coho salmon. Trans. Am. Fish. Soc. 116: 882-890

Salle, A. J. (1954). Fundamental principles of bacteriology, 4th edn. McGraw-Hill Book Company, Inc, New York, Toronto, London

Manuscript first received: May 24, 1989

Revised version accepted: September 21, 1989 